\title{
Pulmonary function of a paediatric cohort of patients with postinfectious bronchiolitis obliterans. A long term follow-up
}

\author{
Alejandro J Colom, ${ }^{1}$ Alberto Maffey, ${ }^{1}$ Facundo Garcia Bournissen, ${ }^{2}$ Alejandro Teper ${ }^{1}$
}

- Additional material is

published online only. To view please visit the journal online (http://dx.doi.org/10.1136/ thoraxjnl-2014-205328).

${ }^{1}$ Respiratory Centre, $\mathrm{R}$ Gutierrez Children's Hospital, Buenos Aires, Argentina ${ }^{2}$ Parasitology and Chagas Service, R Gutierrez Children's Hospital, Buenos Aires, Argentina

\section{Correspondence to}

A J Colom, Respiratory Centre, R Gutierrez Children's Hospital, Gallo 1330, Buenos Aires (1425), Argentina; acolom@gmail.com

Received 10 March 2014 Revised 15 October 2014 Accepted 18 October 2014 Published Online First 11 November 2014

\section{SLinked}

- http://dx.doi.org/10.1136/ thoraxjnl-2014-206168

\section{CrossMark}

$$
\begin{aligned}
& \text { To cite: Colom AJ, } \\
& \text { Maffey A, Garcia } \\
& \text { Bournissen F, et al. Thorax }
\end{aligned}
$$$$
\text { 2015;70:169-174. }
$$

\begin{abstract}
Background Postinfectious bronchiolitis obliterans (BO) is a chronic respiratory disease that usually follows a severe adenovirus infection.

Objective To determine the evolution of pulmonary function and clinical outcome of children with postinfectious BO during childhood.

Methods The study included patients diagnosed with postinfectious BO in whom at least two spirometries were performed within a minimum interval of 3 months. Results 46 met the inclusion criteria. The mean $( \pm S D)$ follow-up period was $12.5( \pm 3.5)$ years. 197 spirometries and 41 plethysmographies were performed. Initial ( $9 \pm 3$ years old) lung function was as follows (z score, mean \pm SD): forced vital capacity (FVC) $-3.8 \pm 1$; forced expiratory volume in $1 \mathrm{~s}\left(\mathrm{FEV}_{1}\right)-4.4 \pm 1$; $\mathrm{FEV}_{1} / \mathrm{FVC}-2.2 \pm 1$; forced expiratory flow $(\mathrm{FEF})_{25-75}$ $-3.7 \pm 1$; total lung capacity (TLC) $120 \pm 26 \%$; residual volume (RV) $309 \pm 108 \%$; and RV/TLC 55 \pm 13 . During childhood, FVC and $\mathrm{FEV}_{1}$ increased by a mean of $11 \% / y e a r(95 \% \mathrm{Cl} 9.3 \%$ to $12.6 \% ; p<0.0001)$ and $9 \% /$ year ( $95 \% \mathrm{Cl} 7.7 \%$ to $10.2 \% ; p<0.0001)$, and the $\mathrm{FEV}_{1} / \mathrm{FVC}$ ratio decreased by $1.9 \%$ /year $(95 \% \mathrm{Cl} 1 \%$ to 2.8; $p<0.001)$. The $z$ score for FVC, FEV 1 and $\mathrm{FEV}_{1} / \mathrm{FVC}$ decreased by 0.07 z score/year $(95 \% \mathrm{Cl} 0.1$ to 0.01 ;

\section{Key messages}

What is the key question?

- Lung function development and the clinical outcome of patients with postinfectious bronchiolitis obliterans throughout childhood remains poorly defined.

What is the bottom line?

- In the past decades, indentification of a growing number of patients that survived a severe insult of the lower respiratory tract, usually due to adenovirus infection, allowed us to perform a prospective cohort study to bring to light the development of lung function and clinical aspects of these patients.

Why read on?

- This large prospective study is the first to systematically examine lung function and clinical outcome of postinfectious bronchiolitis obliterans patients over a follow-up period of more than 12 years.
\end{abstract} $\mathrm{p}<0.05), 0.09$ z score/year $(95 \% \mathrm{Cl} 0.1$ to 0.05 ; $p<0.01)$ and 0.04 z score/year $(95 \% \mathrm{Cl} 0.09$ to 0.001 ; $p<0.02$ ), respectively. During the follow-up period, $69 \%$ of patients required at least one hospital readmission and five required mechanical ventilation. Nine patients developed a thoracic deformity, and seven whose bronchiectasis did not respond to clinical treatment underwent a lobectomy.

Conclusions After a 12 year follow-up period, pulmonary function remained severely impaired, showing an obstructive pattern with air trapping that slowly improved during childhood. An unequal growth of lung parenchyma over the airways suggests dysinaptic growth Patients required frequent readmission due to recurrent respiratory infections, and hypoxaemia improved slowly over time.

\section{INTRODUCTION}

Bronchiolitis obliterans (BO) is an uncommon chronic respiratory disease that generally appears following a severe insult of the lower respiratory tract. Causes may include complications of graft versus host disease in bone marrow transplant recipients, chronic graft rejection in lung transplant recipients and Stevens-Johnson syndrome. In many parts of the world BO is most commonly seen in children after severe viral lower respiratory tract infections. ${ }^{1}$ Postinfectious $\mathrm{BO}$ has been reported mainly in Argentina, ${ }^{2}$ Chile, ${ }^{3}$ Southern Brazil, ${ }^{4}$ and Turkey, ${ }^{5}$ and in native populations in Australia and Canada; ${ }^{6-8}$ other areas, such as the USA and Europe, have reported a small number of patients. ${ }^{9}$ Reasons for the difference in prevalence of the disease may include the severity of the adenovirus infections according to serotype ${ }^{1011}$ and a genetic predisposition to develop the disease. ${ }^{12}$

We previously reported that adenovirus infection and mechanical ventilation are significant risk factors for children developing postinfectious BO. ${ }^{2}$ Hence when an adenovirus infection is detected and the patient does not improve, BO should be suspected.

Postinfectious BO usually occurs in infants younger than 6 months. ${ }^{2}$ Initially, these patients present symptoms that do not differ from severe bronchiolitis. BO is clinically characterised by tachypnoea, increased anteroposterior chest diameter, crackles, wheezing and hypoxaemia for at least 30 days after the initial injury. ${ }^{11}{ }^{13}$ In addition to clinical characteristics, infant pulmonary function 
(PF) shows a severe and fixed airway obstruction, and high resolution chest CT scan shows characteristic mosaic patterns and bronchiectasis. ${ }^{13}{ }^{14}$ During hospital admission, most patients are found to have severe airway obstruction with hypoxaemia, and in many cases mechanical ventilation is required.

We have published a $\mathrm{BO}$ score. The $\mathrm{BO}$ score is a simple to use clinical prediction rule, based on elements that are readily available in most medical centres, and is used widely in our country. ${ }^{15}$ The score is made up of three variables: typical clinical history of postinfectious BO with hypoxaemia (defined as a previously healthy infant, with a severe episode of bronchiolitis and resultant chronic respiratory hypoxaemia for more than 60 days $\left(\mathrm{O}_{2}\right.$ sat $\left.<92 \%\right)$, at rest over $15 \mathrm{~min}$ and breathing room air); history of adenovirus infection; and high resolution CT scan with mosaic pattern. The presence of two of these three variables makes a $\mathrm{BO}$ score of 7 or more, predicting a diagnosis of postinfectious $\mathrm{BO}$ with high accuracy.

Our current knowledge about the outcome of patients with postinfectious BO is based largely on a few series of cases with a short follow-up. ${ }^{3}{ }^{6}$ In 1996, in the Respiratory Centre of the R Gutierrez Children's Hospital, Buenos Aires, Argentina, we began a prospective cohort observational and descriptive study of patients with postinfectious BO.

The objective of this study was to determine the evolution of $\mathrm{PF}$ and clinical outcome of children with postinfectious $\mathrm{BO}$ during childhood.

\section{METHODS}

The study included patients diagnosed with postinfectious $\mathrm{BO}$ between 1996 and 2012 in the Respiratory Centre of R Gutierrez Children's Hospital, Buenos Aires, Argentina, in whom at least two spirometries were performed with a minimum interval between them of $>3$ months.

The diagnosis of postinfectious $\mathrm{BO}$ was based on a positive BO score as well as a high resolution CT scan compatible with $\mathrm{BO}$, and $\mathrm{PF}$ with a severe and fixed obstructive pattern. ${ }^{15}$ Children with cystic fibrosis, congenital heart disease, primary ciliary dyskinesia or immunodeficiencies were excluded. The BO score was calculated by assigning points to the following variables: typical clinical history (4 points), adenovirus infection (3 points) and high resolution CT with mosaic perfusion (4 points). A score of 7 predicts BO diagnosis with a specificity of $100 \%$ (95\% CI $79 \%$ to $100 \%)$ and a sensitivity of $67 \%$ (95\% CI $47 \%$ to $80 \%)^{15}$

Ricardo Gutierrez Children's Hospital is a tertiary care centre associated with Buenos Aires University that receives referrals from all over the country. Ethics approval was granted by local ethics committee.

Based on the national consensus, patients received home oxygen therapy when $\mathrm{SpaO}$ was $<93 \%$. Clinical outcome was assessed during follow-up visits, which included physical examination, anthropometry, pulse oximetry, radiological images and PF tests. During these visits, patients were evaluated by a pulmonologist, cardiologist, nutritionist and caseworker. After discharge from the hospital, visits were planned every 2 weeks, and once they became clinically stable, visits were arranged at least three times a year. The frequency of the follow-up visits was scheduled according to the clinical status of the patient.

PF tests included spirometry and plethysmography. A bronchodilator response to $200 \mu \mathrm{g}$ of albuterol administered by MDI through a volume spacer device with mouthpiece (Aerochamber) was evaluated according to the American Thoracic Society recommendations. PF was evaluated with standardised techniques using a Vmax series 2, Sensormedics. PF tests were obtained when the patient's condition was stable (absence of an acute respiratory tract infection for the last 30 days and no upper airway secretions). The reference equations used to calculate their SD scores were performed according to the global lung function 2012 equations. $^{16}$

\section{Statistical analysis}

Longitudinal panel data analysis was used to assess the change in PF tests over time. Longitudinal data were analysed using generalised linear mixed effects models, as implemented in $\mathrm{R}$ (lme4 library), with random effects specified at the level of the individual. Normal distribution of dependent variables was evaluated using the Shapiro-Wilks test; variables not normally distributed were log transformed before analysis and log normality confirmed with the Shapiro-Wilks test for the transformed variables. CIs $(95 \% \mathrm{CI})$ for generalised linear mixed effects regressions were estimated by Markov Chain Monte Carlo methods, as implemented in WinBUGS and R. ${ }^{17}$

All increases and decreases in PF test values are described as changes in z score for height. Data were analysed using R software 2.10.0 version (26 October 2009) (The R Foundation for Statistical Computing ISBN 3-900051-07-0) and WinBUGS. Statistical significance was assumed at $\mathrm{p}<0.05$ or the $95 \%$ CIs that did not include the null value (1.0), as applicable. All $\mathrm{p}$ values are uncorrected.

\section{RESULTS}

Among a cohort of 155 patients with a diagnosis of postinfectious BO, 46 met the inclusion criteria. In $55 \%$ of these patients an adenovirus had been detected (table 1).

The first PF test in each patient was obtained at the time when they were able to perform the manoeuvre, at an average age of 9 \pm 3 years old. These showed a severe obstructive pattern with air trapping that did not respond to bronchodilators (table 2).

\section{Pulmonary function}

Lung function in our cohort was followed for an average of $12.5 \pm 3.5$ years. Overall, 196 spirometries were performed; the number of studies was different for each patient, with an average of $4.4 \pm 2.3$ spirometries per patient (table 2 ).

As patients grew up, from 5 to 20 years of age, we observed an increase in forced vital capacity (FVC) and forced expiratory volume in $1 \mathrm{~s}\left(\mathrm{FEV}_{1}\right)$ and a decrease in the Tiffenau index. FVC and $\mathrm{FEV}_{1}$ increased by a mean of $11 \%$ year $(95 \% \mathrm{CI} 9.3 \%$ to $12.6 \% ; \mathrm{p}<0.0001)$ and $9 \% /$ year $(95 \%$ CI $7.7 \%$ to $10.2 \%$; $\mathrm{p}<0.0001)$, respectively, and the FEV1/FVC ratio decreased by

Table 1 Study population of patients with postinfectious bronchiolitis obliterans

\begin{tabular}{ll}
\hline $\mathrm{N}$ & 46 \\
Male (\%) & 54 \\
Age at diagnosis (months)* & $14 \pm 3$ \\
CT scan with mosaic perfusion (\%) & 56 \\
Adenovirus infectious detected (\%) & 55 \\
Age (years) at initial lung function* & $9.5 \pm 3$ \\
Duration of follow-up (years)* & $12.5 \pm 3.5$ \\
No of spirometries & 196 \\
Spirometries per patient & \\
Z score BMI* & $4.4 \pm 2.3$ \\
\hline${ }^{*}$ Mean $\pm S D$. & $-0.5 \pm 1.3$ \\
BMI, body mass index.
\end{tabular}


Table 2 Initial lung function of patients with postinfectious bronchiolitis obliterans

\begin{tabular}{lc}
\hline Variable & Values \\
\hline FVC (z score) & $-3.8 \pm 1$ \\
FEV $_{1}$ (z score) & $-4.3 \pm 1$ \\
FEV $_{1} /$ FVC (z score) & $-2.2 \pm 1$ \\
FEF $_{25-75}$ (z score) & $-3.7 \pm 1$ \\
TLC $(\%)_{\text {RV (\%) }}$ & $120 \pm 26$ \\
RV/TLC & $309 \pm 108$ \\
\hline
\end{tabular}

Values are expressed as mean \pm SD.

$\mathrm{FEF}$, forced expiratory flow; $\mathrm{FEV}_{1}$, forced expiratory volume in $1 \mathrm{~s}$; FVC, forced vital capacity; RV, residual volume; TLC, total lung capacity.

$1.9 \%$ per year $(95 \%$ CI $1 \%$ to $2.8 \%$ ) (figure 1 ; see online supplementary table 3 and figure 6). Therefore, a disproportionate increase in FVC compared with $\mathrm{FEV}_{1}$ was observed.

The strongest association between the evolution of spirometric parameters and growth was observed when they were related to the development of height (figure 1). FVC and $\mathrm{FEV}_{1}$ increased by a mean of $2.3 \% / \mathrm{cm}$ of height gained $(95 \% \mathrm{CI}$ $2.1 \%$ to $2.6 \% ; \mathrm{p}<0.0001)$ and $1.8 \% / \mathrm{cm}$ of height gained $(95 \%$ CI $1.6 \%$ to $2.0 \% ; \mathrm{p}<0.0001)$, respectively, and the $\mathrm{FEV}_{1} / \mathrm{FVC}$ ratio decreased by $0.4 \% / \mathrm{cm}$ of height gained $(95 \%$ CI $0.2 \%$ to $0.6 \% ; \mathrm{p}<0.001$ ) (see online supplementary table 3 ).

When spirometric parameters were expressed as z scores, they decreased during growth, showing that the growth of PF in BO patients lags behind that of healthy children. The $\mathrm{z}$ scores for
FVC, $\mathrm{FEV}_{1}$ and of the Tiffenau index decreased by $0.07 \mathrm{z}$ score/year $(95 \%$ CI 0.1 to $0.01 ; \mathrm{p}<0.05), 0.09 \mathrm{z}$ score/year $(95 \%$ CI 0.1 to $0.05 ; \mathrm{p}<0.01)$ and $0.04 \mathrm{z}$ score/year $(95 \% \mathrm{CI}$ 0.09 to $0.001 ; \mathrm{p}<0.02$ ), respectively (figure 2 ; online supplementary table 4 and figure 7 ).

Twenty-eight patients underwent 44 plethysmographies. Initial plethysmography was performed at a mean age of 11 \pm 3.3 years and the results were: total lung capacity (TLC) 120 $\pm 26 \%$, residual volume (RV) $309 \pm 108 \%$ and RV/TLC 55 \pm 13 . The response to albuterol was highly variable; on average it decreased by $4.5 \pm 44 \%$ and $3.31 \pm 26 \%$ for RV and TLC, respectively.

An annual decrease was observed in TLC and RV of $12 \pm 4 \%$ and $12 \pm 11.6 \% /$ year, respectively, in those patients (27 patients) for whom results for more than one plethysmographic study were available.

\section{Clinical outcome}

At the initial assessment of lung function (9.5 \pm 3.3 years), patients had a $\mathrm{z}$ score for height (mean \pm SD) $-1.1 \pm-1.1$, weight $1.48 \pm 0.9$, relationship of weight/height $-0.2 \pm 0.7$ and a body mass index $\mathrm{z}$ score of $-0.5 \pm 1.3$. At the end of the monitoring period ( 20 years old), these parameters had not changed significantly (height $\mathrm{z}$ score $-0.96 \pm 0.85$, weight $\mathrm{z}$ score weight and body mass index $\mathrm{z}$ score $-0.41 \pm 1.7$ ).

Most patients (84\%) required oxygen supplementation for a median of 5 months (IQR 2-26 months) after discharge from the initial hospital admission. Oxygen saturation improved slowly over several years, and only one patient continued to need supplemental oxygen at age 10 years (figure 3). During the
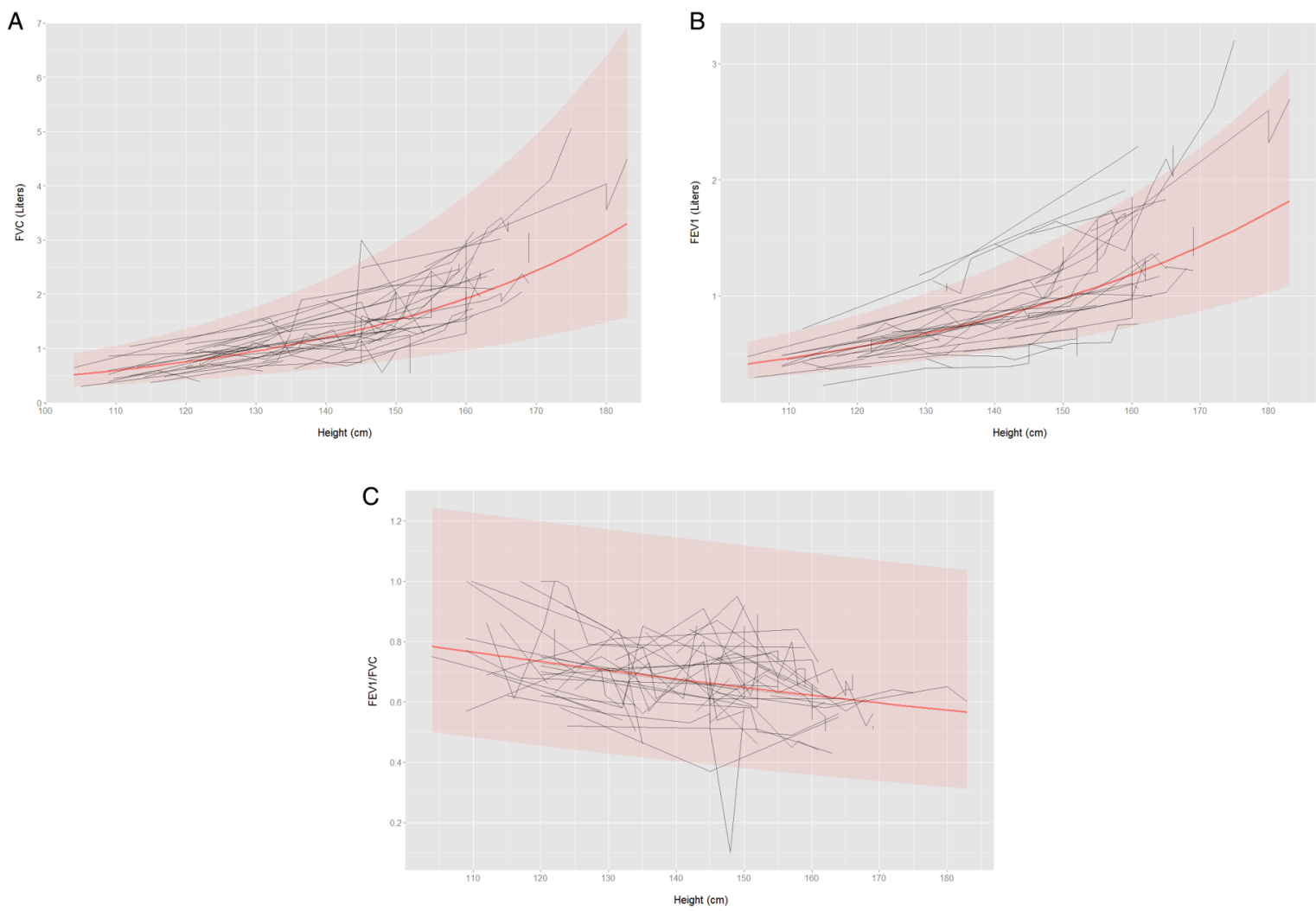

Figure 1 Relationship between pulmonary function tests and the development of height. Longitudinal data analysed using generalised linear mixed effects models. Population regression (red line) and $95 \% \mathrm{Cl}$ (shaded area). Individual data are depicted by black lines. (A) Forced vital capacity (FVC) versus height. Regression performed on log transformed FVC. (B) Forced expiratory volume in $1 \mathrm{~s}$ (FEV F $_{1}$ ) versus height. Regression performed on log transformed $\mathrm{FEV}_{1}$. (C) $\mathrm{FEV}_{1} / \mathrm{FVC}$ ratio versus height. 
A

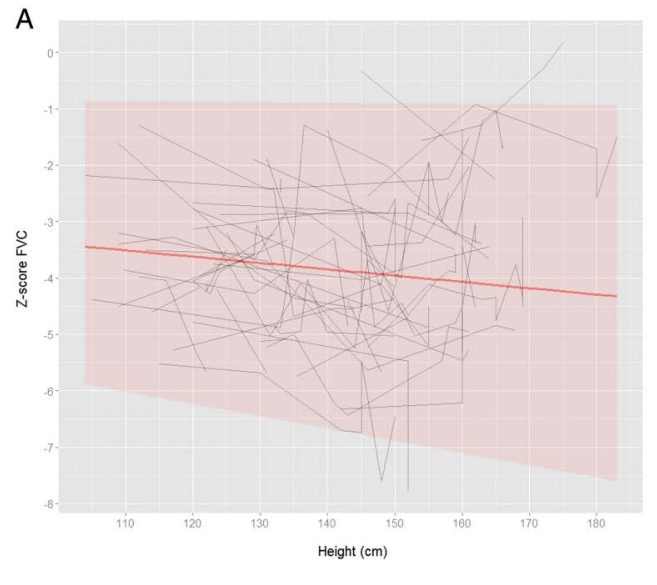

B

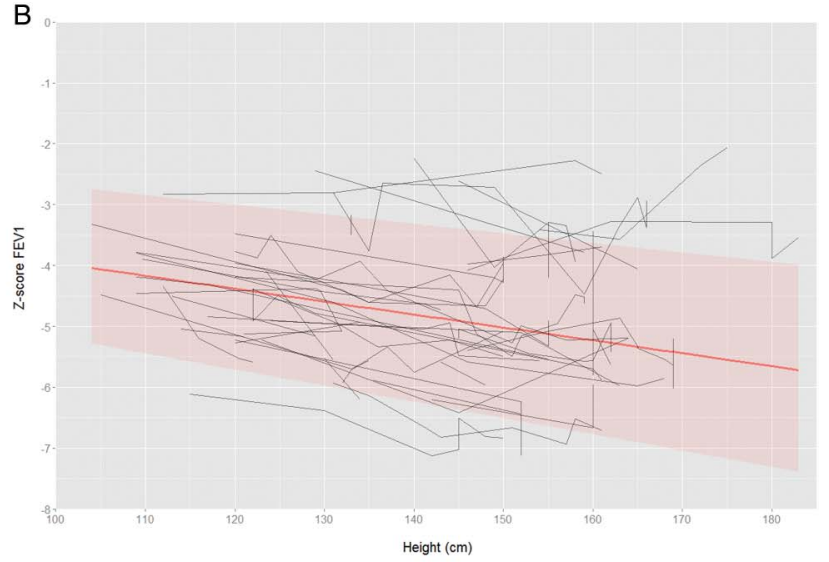

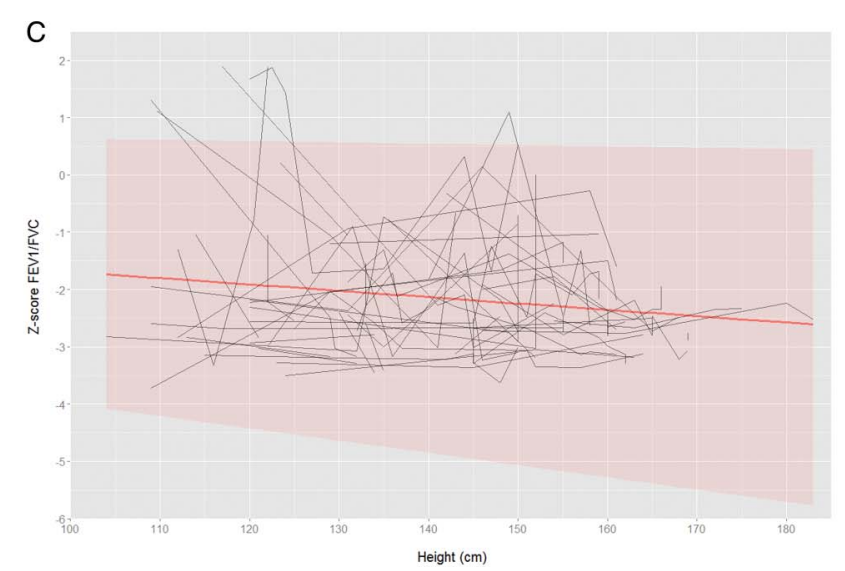

Figure 2 Relationship between pulmonary function, expressed as z score, and the development of height. Longitudinal data analysed using generalised linear mixed effects models. Population regression (red line) and $95 \% \mathrm{Cl}$ (shaded area). Individual data are depicted by black lines. (A) Z score for forced vital capacity (FVC) (expressed as SD from the mean FVC for height) versus height. (B) Z score for forced expiratory volume in $1 \mathrm{~s}$

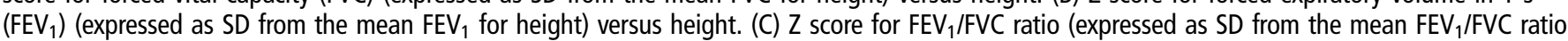
for height) versus height.

follow-up period, $69 \%$ of patients required at least one readmission, which diminished over the years (during the first 2 years the mean number of readmissions was 1.6 , with 0.12 admission/ year/patient thereafter).

Readmissions were mainly due to respiratory infections (96\%) requiring in all cases treatment with antibiotics, bronchodilators and physiotherapy. Five patients required mechanical ventilation during a readmission and one patient died. After 6 years of age, patients showed chest radiographs with air trapping (100\%), atelectasis $(71 \%)$, areas with an increased interstitial pattern $(62 \%)$ and honeycombing (46\%). The most frequent findings

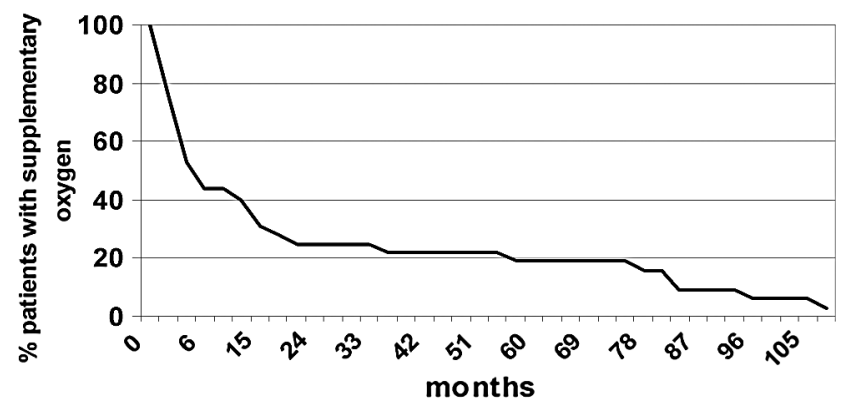

Figure 3 Percentage of patients who received supplementary oxygen from the time of discharge from the initial hospital admission until they were 10 years of age. on high resolution CT scans were bronchiectasis (78\%) and mosaic perfusion $(56 \%)$.

Nine patients developed a thoracic deformity, consisting of an asymmetric pectus carinatum. Three underwent corrective surgery (figure 4). Seven patients whose bronchiectasis did not respond to clinical treatment underwent surgery-six had lobectomies (one or two lobes) and one had a left pneumonectomy. The most commonly affected lobes were middle lobe (3 patients), right upper lobe (3 patients), left lower lobe (1 patient) and right inferior lobe (1 patient) (figure 5). After surgery, none of the patients required ventilator support but complications were frequent $(56 \%$, three wound infections, two pneumothorax and two bronchopleural fistulas).

\section{DISCUSSION}

In this study, among children with postinfectious BO, after more than a 12 year follow-up period, patients showed severely impaired PF with an obstructive pattern with severe air trapping (table 2) that improved slowly with growth (figure 1). Hypoxaemia also improved over time (figure 3) but patients required frequent readmission to hospital because of recurrent respiratory infections.

Although a mixed pattern has been described by other authors, ${ }^{9}$ in the present study all patients had a pattern of PF characterised by obstruction of the medium to small airways with consequent air trapping, as indicated by an increased RV\% and RV/TLC ratio (table 2). 


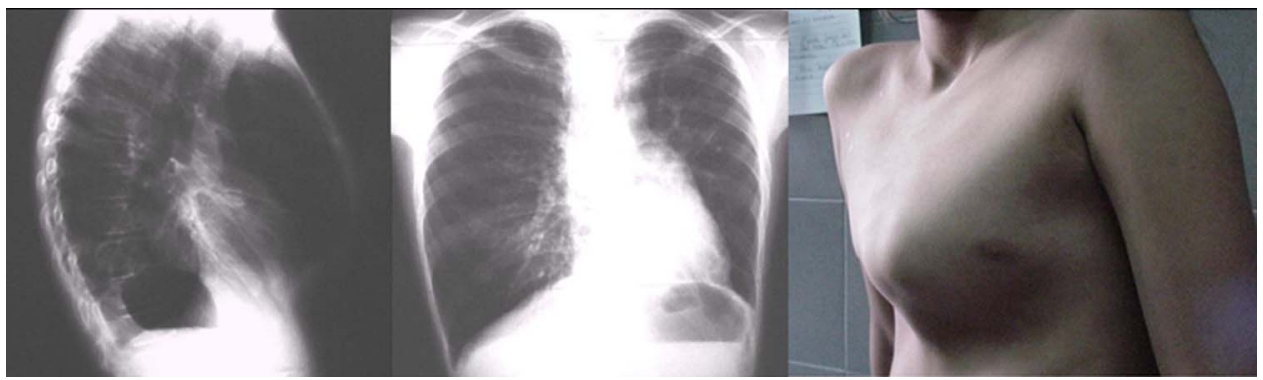

Figure 4 Radiological images and thoracic deformity of a patient with postinfectious bronchiolitis obliterans at 11 years of age.

The obstructive lung disease seen in our study was as expected, but conflicting results have been reported regarding its progression in childhood. A previous study, including only 11 patients with postinfectious $\mathrm{BO}$, reported that PF declined with growth. ${ }^{19}$ In our patients, however, although the $\mathrm{z}$ scores for FVC and $\mathrm{FEV}_{1}$ decreased (figure 2), values for FVC and $\mathrm{FEV}_{1}$ increased at the same time as they grew up from 5 to 20 years of age (figure 1), showing that the development of lung function in BO patients is slower or lower than in healthy children. Ethnicity, and genetic and social factors may contribute to these differences, as the prevalence of the disease in South America is one of the highest reported. The fact that FVC increased more than $\mathrm{FEV}_{1}$ could be explained by an unequal growth of lung parenchyma and airways, indicative of a 'dysynaptic growth' of the lung (figure 1). The most likely explanation for this lung growth may be the concept of the neoalveolisation throughout childhood and adolescence postulated by Narayanan et al. However, this catch-up growth after the lung injury could be possible in terms of alveolar number, but may be not as much for airway size. ${ }^{20} 21$

Similar to healthy children, the strongest association between the development of lung function values and growth in $\mathrm{BO}$ patients was observed when they were associated with the development of height (figure 1).

While the mean bronchodilator response in $\mathrm{FEV}_{1}$ was nearly $12 \%$, RV diminished by less than $200 \mathrm{~mL} .^{22}$ Patients with a significant bronchodilator response $\left(>12 \%\right.$ in $\mathrm{FEV}_{1}$ and $>200 \mathrm{~mL}$ in RV) were few but are important to identify because in these patients bronchodilators can help improve lung function.

Although spirometric parameter values increased, PF remained severely impaired in childhood. In the same way, plethysmographic studies showed a decrease in air trapping.

Quality of life, to the extent that patients no longer needed supplemental oxygen and had less hospital readmissions, was at least in part the result of the development of PF (figure 3).
Unlike other studies that reported remission of the pulmonary sequelae, ${ }^{34}$ we did not observe remissions in our patients, possibly because we included a homogeneous group of patients with severe lung damage (table 2) while other studies may have included patients with milder forms of the disease.

In childhood, 6 years after the beginning of the disease, our cohort of BO patients showed a suitable nutritional status. This condition may be the result of the balance between a high nutritional input and high nutritional requirements due to the increased respiratory work; furthermore, some patients with a very low income (due to socioeconomic conditions) showed important nutritional deficiencies.

Enhancing overall growth should be one of the main objectives in the treatment of these patients, because even with irreparable lung damage, physical maturation is the key to the development of the lung and the last chance to improve lung function and quality of life.

An interesting observation was the development of thoracic deformities following postinfectious BO (figure 4); other diseases such as bronchopulmonary dysplasia, ${ }^{23} 24$ severe asthma ${ }^{25}$ and congenital heart disease have also been reported to cause thoracic deformities. $^{26}$ Three of our patients with thoracic deformities underwent corrective surgery and did not develop post surgical complications. We speculate that the abnormalities resulted from a combination of demineralised bones and chronic air trapping. It is plausible that these chest wall deformities may be clinically deleterious due to interference with respiratory mechanics. ${ }^{18}$

The main treatment objective is tailored control for each patient according to lung damage and clinical response. Some patients required more courses of antibiotics and chest physiotherapy because of bronchiectasis (figure 5), and a few patients had a significant response to bronchodilators. In spite of the various treatments, lung damage was irreversible. Other studies have suggested a potential role for maintenance
Figure 5 CT scan of patients with postinfectious bronchiolitis obliterans showing bronchiectasis. Left: patient with total collapse of the right lung with bronchiectasis. Note the hyperinsuflation of the left lung. Right: patient with bronchiectasis in the right and left lower lobes.

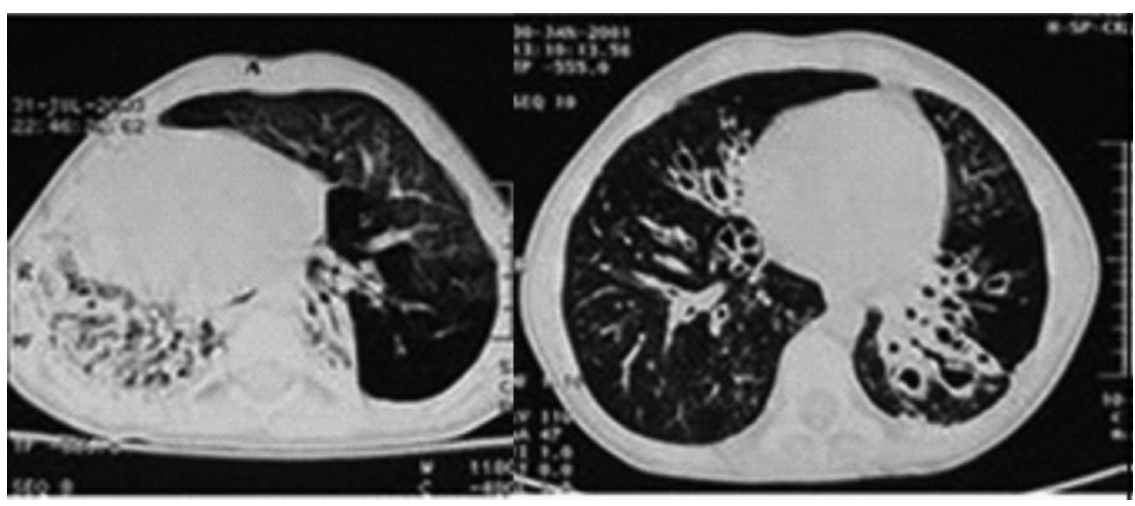


macrolide therapy in $\mathrm{BO}$ following bone marrow or lung transplantation; $;^{27-29}$ another study described successful treatment of $\mathrm{BO}$ in a bone marrow transplant patient with tumour necrosis factor $\alpha$ blockade (Infliximab). ${ }^{30}$ We have not evaluated the potential benefits of these treatments in postinfectious $\mathrm{BO}$.

An important decision in the treatment of patients with postinfectious $\mathrm{BO}$ is whether to perform a lobectomy as $\mathrm{PF}$ is severely impaired and most patients develop complications after surgery. In patients who have bronchiectasis localised primarily to one lobe and in whom clinical treatment has failed, reducing quality of life, surgery may be a useful alternative.

Important factors to consider in future research include the ideal timing, dosage and best choice of immunosuppressive agents to avoid BO development. Clinical trials of potential therapeutic agents should be multicentric in order to include a significant number of patients.

We conclude that after a 12 year follow-up period, PF remained severely impaired, showing an obstructive pattern with air trapping that slowly improved during childhood. This improvement may be mainly due to the development of lung parenchyma more than airway growth. Patients required frequent readmission to hospital due to recurrent respiratory infections, and hypoxaemia improved slowly over time.

Acknowledgements The authors thank Dr Sonia Buist and the staff of the American Thoracic Society Methods in Epidemiologic, Clinical and Operations Research (MECOR) for encouraging our research and helping to improve the paper.

Contributors AJC made substantial contributions to the conception and design of the work, which consisted of the acquisition, analysis and interpretation of the data. He wrote the original draft. AM made substantial contributions to the conception and design of the work, which consisted of acquisition of the data. He contributed to the original draft. FGB made substantial contributions to the conception and design of the work, which consisted of analysis and interpretation of the data. He contributed to the original draft. AT made substantial contributions to the conception and design of the work. He contributed to the original draft. All authors agree to be accountable for all aspects of the work in ensuring that questions related to the accuracy or integrity of any part of the work are appropriately investigated and resolved.

\section{Competing interests None.}

Ethics approval The study was approved by the Comité de ética en investigación, Hospital de Niños R Gutiérrez.

Provenance and peer review Not commissioned; externally peer reviewed.

\section{REFERENCES}

1 Hardy KA, Schidlow DV, Zaeri N. Obliterative bronchiolitis in children. Chest 1988;93:460-6.

2 Colom AJ, Teper AM, Vollmer WM, et al. Risk factors for the development of bronchiolitis obliterans in children with bronchiolitis. Thorax 2006;61:503-6.

3 Castro-Rodriguez J, Daszenies C, Garcia M, et al. Adenovirus pneumonia in infants and factors for developing bronchiolitis obliterans: a 5-year follow-up. Pediatr Pulmonol 2006;41:947-53.

4 Zhang L, Irion K, Kozakewich $\mathrm{H}$, et al. Clinical course of postinfectious bronchiolitis obliterans. Pediatr Pulmonol 2000;29:341-50.
5 Yalçın E, Dogru D, Haliloglu M, et al. Postinfectious bronchiolitis obliterans in children: clinical and radiological profile and prognostic factors. Respiration 2003;70:371-5

6 Lang W, Howden C, Laws J, et al. Bronchopneumonia with serious sequelae in children with evidence of adenovirus type 21 infection. BMJ 1969;1:73-9.

7 Wenman W, Pagtakhan R, Reed M, et al. Adenovirus bronchiolitis in Manitoba. Epidemiologic, clinical and radiologic features. Chest 1982;81:605-9.

8 Chang A, Masel J, Masters B. Post-infectious bronchiolitis obliterans: clinical, radiological and pulmonary function sequelae. Pediatr Radiol 1998;28:23-9.

9 Kim CK, Kim SW, Kim JS, et al. Bronchiolitis obliterans in the 1990s in Korea and the United States. Chest 2001;120:1101-6.

10 Becroft DMO. Bronchiolitis obliterans, bronchiectasis, and other sequelae of adenovirus type 21 infection in young children. J Clin Pathol 1971;24:72-82.

11 Simila S, Linna O, Lanning P, et al. Chronic lung damage caused by adenovirus type 7: a ten year follow up study. Chest 1981;80:127-31.

12 Wohl ME, Chernick V. State of the art: bronchiolitis. Am Rev Respir Dis 1978;118:759-81.

13 Teper $A M$, Kofman $C D$, Maffey $A F$, et al. Lung function in infants with chronic pulmonary disease after severe adenoviral illness. J Pediatr 1999;134:730-3.

14 Copley SJ, Padley SPG. High-resolution CT of paediatric lung disease. Eur Radiol 2001;11:2564-75.

15 Colom AJ, Teper AM. Clinical prediction rule to diagnose post-infectious bronchiolitis obliterans in children. Pediatr Pulmonol 2009;44:1065-9.

16 Quanjer PH, Stanojevic S, Cole TJ, et al. Multi-ethnic reference values for spirometry for the 3-95 year age range: The global lung function 2012 equations. Eur Respir 」 2012;40:1324-43.

17 Lunn DJ, Thomas A, Best N, et al. WinBUGS-a Bayesian modelling framework: concepts, structure, and extensibility. Stat Comput 2000;10:325-37.

18 Castile RG, Staats BA, Westbrook PR. Symptomatic pectus deformities of the chest. Am Rev Respir Dis 1982;126:564-8.

19 Cazzato S, Poletti V, Bernardi F, et al. Airway inflammation and lung function decline in childhood post-infectious bronchiolitis obliterans. Pediatr Pulmonol 2008:43:381-90.

20 Narayanan M, Beardsmore CS, Owers-Bradley J, et al. Catch-up alveolarization in ex-preterm children. Evidence from ${ }^{3} \mathrm{He}$ magnetic resonance. Am J Respir Crit Care Med 2013:187:1104-9.

21 Narayanan M, Owers-Bradley J, Beardsmore CS, et al. Alveolarization continues during childhood and adolescence: new evidence from helium-3 magnetic resonance. Am J Respir Crit Care Med 2012;185:186-91.

22 Wanger J, Clausen J, Coates A, et al. Standardisation of the measurement of lung volumes. Eur Respir J 2005;26:511-22.

23 De Boeck K, Smith J, Van Lierde S, et al. Flat chest in survivors of bronchopulmonary dysplasia. Pediatr Pulmonol 1994;18:104-7.

24 Edwards DK III, Hilton SW. Flat chest in chronic bronchopulmonary dysplasia. AJR Am J Roentgenol 1988;150:375.

25 Fraser $\mathrm{R}$, Pare $\mathrm{P}$, Pare $\mathrm{P}$, et al. Diagnosis of diseases of the Chest (translation: Patrone U, Meerof N). Buenos Aires 1992:2744-55.

26 Davies H. Chest deformities in congenital heart disease. $\mathrm{Br} J$ Dis Chest 1959:53:151-9.

27 Gerhardt S, McDyer J, Girgis R, et al. Maintenance azithromycin therapy for bronchiolitis obliterans syndrome. Results of a pilot study. Am J Respir Crit Care Med 2003;168:121-5.

28 Mistchenko AS, Lenzi HL, Thompson FM, et al. Participation of immune complexes in adenovirus infection. Acta Paediatr 1992;81:983-8.

29 Mistchenko AS, Diez RA, Mariani AL, et al. Cytokines in adenoviral disease in children: association of interleukin-6, interleukin-8, and tumor necrosis factor alpha levels with clinical outcome. J Pediatr 1994;124:714-20.

30 Fullmer J, Fan L, Dishop M, et al. Successful treatment of bronchiolitis obliterans in a bone marrow transplant patient with tumor necrosis factor- $\alpha$ blockade. Pediatrics 2005;116:767-70. 